\title{
Steroidogenesis and prostaglandin synthesis by cultured bovine blastocysts
}

\author{
M. Shemesh, F. Milaguir, N. Ayalon* and W. Hansel† \\ Departments of Hormone Research and ${ }^{*}$ Reproduction, Kimron Veterinary Institute, Beit \\ Dagan, Israel, and $\dagger$ Department of Physiology and Physical Biology, Cornell University, \\ Ithaca, New York, U.S.A.
}

\begin{abstract}
Summary. Bovine blastocysts were collected at Days 13,15 and 16 and placed in TCM-199 supplemented with 5\% fetal calf serum; some blastocysts were immediately frozen while the others were cultured for $48 \mathrm{~h}$ and then frozen. Samples (tissue + medium, 5-12/group) were thawed, homogenized and analysed by radioimmunoassays. Measurable amounts of progesterone were found in all blastocysts but values were higher $(P<0.01)$ after culture. Testosterone was not found in the cultured or uncultured blastocysts at Day 13, but was detectable on Days 15 and 16 and in greater amounts $(P<0.05)$ in the cultured blastocysts. PGF and PGE-2 were increased $(P<0.05)$ in the cultured blastocysts on all 3 days. Oestradiol was measurable in some but not all blastocysts. It is suggested that PG synthetase and enzymes capable of synthesizing progesterone, testosterone and, possibly, oestradiol are present in these early bovine blastocysts.
\end{abstract}

\section{Introduction}

It is not clear whether bovine blastocysts can synthesize sterols and steroids and transform them to other steroid hormones. Huff \& Eik-Nes (1966) showed that rabbit blastocysts contain enzyme systems capable of synthesizing cholesterol and pregnenolone from acetate, and catalysing steroid metabolism. Huff \& Eik-Nes (1966) also demonstrated that a mixture of growth hormone and luteinizing hormone supported development as far as a first segment embryo during a 7-day incubation period. Seamark \& Lutwak-Mann (1972) found significant concentrations of progesterone, 20a-dihydroprogesterone and $17 \alpha$-hydroxyprogesterone in the blastocyst and blastocyst fluid of the rabbit. These authors suggested that the presence of large amounts of progesterone in uterine fluid could indicate that progesterone is not synthesized by blastocysts but is transferred to them via uterine secretions. Perry, Heap \& Amoroso (1973) demonstrated the presence of unconjugated oestrogens, as well as progesterone, in pig blastocysts, and provided biochemical evidence for the presence within the blastocyst tissue of aromatase, 17-20 desmolase and 3-sulphatase enzyme systems, all of which are concerned with the production of oestrogens from neutral steroids. Perry et al. (1973) suggested that the presence of unconjugated oestrogen and progesterone in pig blastocyst tissue is probably a result of synthesis in situ and not a result of diffusion from the maternal circulation. Dickmann, Dey \& Sen Gupta (1975) demonstrated histochemically the presence of both $\Delta^{5}, 3 \beta$-hydroxysteroid dehydrogenase $\left(\Delta^{5}, 3 \beta\right.$-HSD) and $17 \beta$-hydroxysteroid dehydrogenase (17 $\beta$-HSD) activities in 6 day rabbit blastocysts and suggested that blastocysts of this age have the enzymic capacity to synthesize progesterone and oestrogens.

In the present study, the accumulation of progesterone, testosterone, oestradiol and prostaglandins by cultured bovine blastocysts was compared with that of uncultured blastocysts. 


\section{Materials and Methods}

Superovulation was induced in normal Holstein-Friesian cows which were then inseminated. Blastocysts were recovered at 13,15 or 16 days after oestrus by flushing the uterine horns with a large volume $(700 \mathrm{ml})$ of sterile medium consisting of $0.1 \mathrm{M}$-sodium phosphate buffer $(\mathrm{pH} \mathrm{7.2)}$ supplemented with $0.1 \%$ glucose and bovine serum albumin $(5 \mathrm{mg} / \mathrm{ml})$. The numbers of cows supplying the blastocysts for each day are shown in Tables 1 and 2 . The blastocysts from each cow were removed from the uterine flushings, washed with the medium and placed in $1 \mathrm{ml}$ medium in glass vials and stored at $-20^{\circ} \mathrm{C}$ or cultured in TCM-199 containing Eagle's salts and $25 \mathrm{mM}$-HEPES buffer, $\mathrm{pH} 7 \cdot 5$, supplemented with $5 \%$ fetal calf serum and $50 \mu \mathrm{g}$ gentamycin $/ \mathrm{ml}$. Blastocysts of similar age and size were cultured for $48 \mathrm{~h}$ in an incubator at $37^{\circ} \mathrm{C}$, continuously flushed with $95 \%$ air and $5 \% \mathrm{CO}_{2}$ saturated with water.

\section{Hormone extraction and purification}

At the end of the incubations the tissue and media were frozen until required for assay. The samples were then thawed and homogenized. A small portion (1/10 vol.) served for prostaglandin (PG) determination (Shemesh \& Hansel, 1975). Tritiated progesterone, testosterone and oestradiol-17 $\beta$ (sp. act. 80-110 Ci/mmol; New England Nuclear, Boston, Massachusetts) were added to each sample. The samples were then extracted with petroleum ether $(30-60)$ to remove progesterone and with ethyl ether to remove oestradiol-17 $\beta$ and testosterone. The solvents were dried under $\mathrm{N}_{2}$ at $30^{\circ} \mathrm{C}$. Column chromatography of the oestradiol and testosterone were accomplished on Sephadex LH-20 with benzene-methanol $(9: 1 \mathrm{v} / \mathrm{v})$. Progesterone separation was also accomplished on Sephadex LH-20 using hexane-benzene-methanol $(9: 1: 1 \mathrm{v} / \mathrm{v})$. The average recoveries of known amounts $(100-500 \mathrm{pg})$ of steroid added to 20 replicates were (mean \pm s.e.m.) $87 \pm 7 \%$ for progesterone, $72 \pm 13 \%$ for oestradiol, $76 \pm 9 \%$ for testosterone, $108 \%$ for PGF and $102 \%$ for PGE- 2 . The average recoveries determined after addition of tracer amounts to 58 samples were $92 \pm 6,85 \pm 11$ and $80 \pm 6 \%$, for progesterone, oestradiol and testosterone, respectively, and $96 \pm 3 \%$ for PGF.

\section{Assays}

In a series of preliminary experiments it was established that the medium used contained undetectable amounts of each of the hormones measured. Progesterone, oestrogen and testosterone remained undetectable following incubation; small but measurable $(30 \mathrm{pg})$ concentrations of PGF and PGE were found after incubation. The limit of sensitivity for each of the assays was $5 \mathrm{pg}$. No blank problems were encountered following incubation or after use of the Sephadex LH-20 columns. All samples were assayed in duplicate.

Testosterone. An antiserum raised in the rabbit against testosterone-3-(O-carboxymethyl)oxime-BSA was used for the radioimmunoassay. This antiserum reacts preferentially with testosterone, but cross-reacts with $5 a$-dihydrotestosterone $(50 \%)$ and to a limited extent $(0.001 \%)$ with a variety of other steroids (progesterone, cortisol, oestradiol, oestrone, oestriol, androstenedione). Separation of free from antibody-bound testosterone was accomplished with dextran-coated charcoal, as described previously by Shemesh \& Hansel (1974). The inter- and intra-assay coefficients of variation were 8.9 and $6.7 \%$ respectively.

Progesterone. Progesterone was measured by radioimmunoassay, essentially as described by Shemesh \& Hansel (1975), using an antiserum raised in rabbits against progesterone-11 $\alpha$-hemisuccinate-BSA conjugate. This antiserum reacts only to a negligible extent $(0.001 \%)$ with the above mentioned steroids. The inter- and intra-assay coefficients of variation were 11 and $9 \%$ respectively. 
Oestradiol-17 $\beta$. A specific antiserum against oestradiol-17ß-(6-O-carboxymethyl)-oximeBSA was used. This antiserum cross-reacts to some extent (3\%) with oestrone and to a negligible extent $(<0.001 \%)$ with other steroids. The radioimmunoassay method of Echternkamp \& Hansel (1973) was used for oestradiol determination. The coefficients of variation between and within assays were 7 and $10 \%$ respectively.

Prostaglandins. PGF and PGE were determined by radioimmunoassay as described by Shemesh \& Hansel (1975), using a specific antiserum to total PGF. This antiserum reacts preferentially with PGF-2 but cross-reacts with PGF-1 (50\%) and to a negligible extent (0.1\%) with PGs of the A, B and E series. The antiserum to PGE-2 reacts preferentially with PGE-2 but cross-reacts to some extent (10\%) with PGE-1, PGA-2, PGB-2 and to a minor extent (0.5\%) with PGF-1 and PGF-2. The antisera for PGF and PGE were generous gifts of Dr F. Kohen, Weizmann Institute, Israel. The within-assay coefficients of variation were 9 and $11 \%$ and the between-assay coefficients of variation were 12.3 and $13 \%$ for the PGF and PGE-2 assays respectively.

\section{Statistical analysis}

All data were subjected to analysis of variance and comparisons were made by Student's $t$ test or Tukey's hsd procedure (Steel \& Torrie, 1960).

\section{Results}

The results are shown in Table 1. Measurable amounts of progesterone were found in the cultured and uncultured blastocysts at 13,15 and 16 days after insemination, but the values for the cultured blastocysts were significantly higher than for those of the same age but not cultured. Testosterone could not be demonstrated in the cultured or uncultured blastocysts at the 13th day of age, but measurable amounts, higher in the cultured blastocysts, were found at Days 15 and

Table 1. The mean \pm s.e.m. values (per blastocyst) of progesterone, testosterone, PGF and PGE-2 present in uncultured bovine blastocysts and blastocysts (+ medium) cultured for $48 \mathrm{~h}$

\begin{tabular}{|c|c|c|c|}
\hline & \multicolumn{3}{|c|}{ Age of blastocyst (days) } \\
\hline & 13 & 15 & 16 \\
\hline No. of cows & 8 & 4 & 4 \\
\hline No. of blastocysts & 12 & 11 & 6 \\
\hline \multicolumn{4}{|l|}{ Progesterone (pg) } \\
\hline Uncultured & $60 \pm 12$ & $199 \pm 136$ & $120 \pm 59$ \\
\hline Cultured & $320 \pm 100^{*}$ & $769 \pm 130^{\dagger}$ & $907 \pm 137^{*}$ \\
\hline \multicolumn{4}{|l|}{ Testosterone (pg) } \\
\hline Uncultured & N.D. & $67 \pm 14$ & $47 \pm 8$ \\
\hline Cultured & N.D. & $191 \pm 14^{*}$ & $161 \pm 40 \dagger$ \\
\hline No. of cows & 8 & 4 & 4 \\
\hline No. of blastocysts & 12 & 7 & 5 \\
\hline \multicolumn{4}{|l|}{ PGF (ng) } \\
\hline Uncultured & $12 \pm 3$ & $49 \pm 19$ & $312 \pm 90$ \\
\hline Cultured & $150 \pm 30^{*}$ & $406 \pm 114 \dagger$ & $1142 \pm 234 \dagger$ \\
\hline \multicolumn{4}{|l|}{ PGE-2 (ng) } \\
\hline Uncultured & $3 \pm 0.2$ & $9 \pm 2$ & $35 \pm 11$ \\
\hline Cultured & $53 \pm 18^{*}$ & $35 \pm 10 \dagger$ & $390 \pm 110^{\dagger}$ \\
\hline
\end{tabular}

Significantly different from value for uncultured blastocysts of that age, $* P<0.001 ; \dagger P<0.05$.

N.D., not detectable. 
16. Measurable amounts of PGF and PGE were detected in all the blastocysts at all three ages. There was a steady and significant $(P<0.001)$ rise with age and the values in the cultured blastocysts and medium were 4 to 17 times greater than those of the uncultured blastocysts. Oestradiol-17 $\beta$ was undetectable in the uncultured blastocysts (a total of $<50 \mathrm{pg}$ ), but some, aithough not all, of the cultured blastocysts secreted measurable amounts; the mean ( \pm s.e.m.) concentration was $80 \pm 15 \mathrm{pg}$ oestradiol-17//blastocyst $(n=6)$ at Days 15 and 16 .

The lengths of the blastocysts were within the ranges reported by others (for example, see Staples, McEntee \& Hansel, 1961) and they appeared normal in all respects. Other Day-13 blastocysts produced by the same technique at the same time as those used in these experiments were transferred to recipient animals and normal pregnancies resulted. Although no consistent measurements were made, the smaller blastocysts appeared to increase $20-30 \%$ in length during culture.

\section{Discussion}

The present data show that bovine blastocysts at 13,15 and 16 days of age have the enzymic capacities to produce progesterone, testosterone and prostaglandins, compounds which may have significance for blastocyst development. Kuehl, Cirillo, Ham \& Humes (1973) reported that prostaglandins exert a regulatory role on cyclic AMP and this might affect steroidogenesis. Dickmann \& Spilman (1975) showed that rabbit blastocysts contain PGF and PGE, and we (M. Shemesh, S. Lavi, F. Mileguir, M. Ailenberg \& N. Ayalon, unpublished) have suggested that prostaglandins might act as mediators in bovine blastocyst steroidogenesis.

Although bovine fetal gonads have been shown to produce testosterone and oestradiol by Day 42 of gestation (M. Shemesh, M. Ailenberg, F. Mileguir \& N. Ayalon, unpublished), it seems likely that the fetal trophoblast was responsible for the synthesis of these compounds at this early stage of development. It is at precisely this time (Day 15) that mesoderm formation begins and bi-nucleated giant cells first appear in bovine embryos (Staples et al., 1961). Greenstein, Murray \& Foley (1958) suggested that the bi-nucleated giant cells may produce a gonadotrophin-like substance and Hansel, Lukaszewska \& Beal (1978) have reported that extracts of Day-18 bovine embryos stimulated progesterone synthesis by dispersed bovine luteal cells. Although no gonadotrophin-like activity has been demonstrated for bovine blastocysts, the possibility that such substances were stimulating the steroidogenesis observed in this study can not be excluded.

We thank John Pike of the Upjohn Company for the gift of prostaglandins. This study was supported by a grant from the United States-Israel Binational Science Foundation (BSF), Jerusalem, Israel (Grant No. 1260).

\section{References}

Dickmann, Z. \& Spilman, C.H. (1975) Prostaglandin in rabbit blastocysts. Science, N.Y. 190, 997-998.

Dickmann, Z., Dey, S.K. \& Sen Gupta, J. (1975) Steroidogenesis in rabbit preimplantation embryos. Proc. natn. Acad. Sci. U.S.A. 72, 298-300.

Echternkamp, S.E. \& Hansel, W. (1973) Concurrent changes in bovine plasma hormone levels prior to and during the first postpartum estrous cycle. $J$. Anim. Sci. 37, 1362-1370.

Greenstein, J.S., Murray, R.W. \& Foley, R.C. (1958) Observations on the morphogenesis and histo- chemistry of the bovine pre-implantation placenta between 16 and 33 days of gestation. Anat. Rec. 132 , 331-341.

Hansel, W., Lukaszewska, J. \& Beal, W. (1978) Maintenance of the bovine corpus luteum of early pregnancy. Biol. Reprod. 18, Suppl. 1, 27A, Abstr.

Huff, R.L. \& Eik-Nes, K.B. (1966) Metabolism in vitro of acetate and certain steroids by six-day old rabbit blastocysts. J. Reprod. Fert. 11, 57-63.

Kuehl, F.A., Cirillo, V.J., Ham, E.A. \& Humes, J.L. (I973) The regulatory role of the prostaglandins of 
the cyclic 3,5-AMP system. Adv. Biosci. 9, 155172.

Perry, J.S., Heap, R.B. \& Amoroso, E.C. (1973) Steroid hormone production by pig blastocysts. Nature, Lond. 245, 45-49.

Seamark, R.F. \& Lutwak-Mann, C. (1972) Progestins in rabbit blastocysts. J. Reprod. Fert. 29, 147-148.

Shemesh, M. \& Hansel, W. (1974) Measurement of bovine serum testosterone by radioimmunoassay (RIA) and by a rapid competitive protein binding (CPB) assay. J. Anim. Sci. 39, 720-724.
Shemesh, M. \& Hansel, W. (1975) Arachidonic acid and bovine corpus luteum function. Proc. Soc. exp. Biol. Med. 148, 243-246.

Staples, R.E., McEntee, K. \& Hansel, W. (1961) Luteal function as related to pituitary and ovarian cytology and embryo development in the bovine. J. Dairy Sci. 44, 2049-2057.

Steel, R.G.D. \& Torrie, J.H. (1960) Principles and Procedures of Statistics with Special Reference to the Biological Sciences. McGraw-Hill Book Co., New York. 